\title{
Critical Assessment of Two-Teaching Methods on the Academic Performance of Community Health Students of Ekiti State College of Health Sciences and Technology, Ijero, South-Western, Nigeria
}

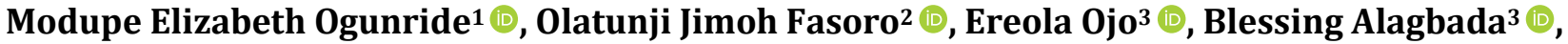 Shegun Victor Oluwatuyi ${ }^{3 *}$ (1)}

\author{
${ }^{1}$ Department of Community Health, Ekiti State College of Health Sciences and Technology, Ijero, Nigeria \\ ${ }^{2}$ Department of Pharmacy, Ekiti State College of Health Sciences and Technology, Ijero, Nigeria \\ ${ }^{3}$ Department of Public Health, Ekiti State College of Health Sciences and Technology, Ijero, Nigeria \\ Email: *diademofglory6797@gmail.com
}

How to cite this paper: Ogunride, M. E., Fasoro, O. J., Ojo, E., Alagbada, B., \& Oluwatuyi, S. V. (2020). Critical Assessment of Two-Teaching Methods on the Academic Performance of Community Health Students of Ekiti State College of Health Sciences and Technology, Ijero, South-Western, Nigeria. Creative Education, 11, 1730-1740. https://doi.org/10.4236/ce.2020.119126

Received: August 22, 2020

Accepted: September 20, 2020

Published: September 23, 2020

Copyright $\odot 2020$ by author(s) and Scientific Research Publishing Inc. This work is licensed under the Creative Commons Attribution International License (CC BY 4.0).

http://creativecommons.org/licenses/by/4.0/

\begin{abstract}
Introduction: Teaching method has varied impact on the academic performance of students across all levels of Education in Nigeria. Objective: The objectives of the study were tailored towards assessing the effectiveness of Two-Methods (Lecture and Practical demonstration) on the academic performance of students in the department of community health. Methodology: The Authors adopted a descriptive research technique using quantitative and qualitative data. The results were analyzed using simple percentage, graphs, charts, mean, SD, Variance, ANOVA, t-test @ 0.05 significant level using STATA MP12, SPSS and graphs. Result: The study revealed that the two-teaching methods (Lecture and Practical demonstration) were found to be effective. Conclusion: It was concluded that the two-teaching are effective in the department and as such recommended that Practical demonstration and Lecture method should be integrated as an effective teaching method for Health Students since it is learner centered.
\end{abstract}

\section{Keywords}

Education, Academic Performance, Health Institution, Teaching Methods, Effectiveness 


\section{Introduction}

Teaching methods are tools utilized in passing knowledge to students and they are used by teachers or lecturers at higher level to impart knowledge to achieve a desired result (Agbele et al., 2020). They are used to impart knowledge to students they are the means by which the teacher attempts to impart the desired learning or experience (Agboola \& Oloyede, 2007). The choice of a particular method of teaching by the teacher determined by number of factors which includes the content to be taught, the objectives which the teacher plans to achieve availability of teaching and learning resources and the ability and willingness of the teacher to improvise if convectional teaching aids are not available, evaluation and follow-up activities and Individual learner differences (Asikhia, 2010). Techniques utilized in teaching are different and vary based on the information, resources, personnel or skills that is being taught and also be influenced by the aptitude and enthusiasm of the student. Various studies had been conducted concerning teaching methods, for example Asikhia (2010), found that, qualification of teachers and students' environmental factors do not influence students poor performance but teachers' methods of teaching influence poor academic performance. In Health, there are various teaching methods commonly used teaching methods especially in developing countries like Nigeria (Berry, 2008). Practical demonstration is becoming primus inter-pares in health institutions in Nigeria while more attention is given to online learning due to the on-going lockdown measures in place due to COVID-19 pandemic in Nigeria (Faraday, Overton, \& Cooper, 2011). However, more recently there is an argument in education industry to adopt a learner-cantered paradigm shift (Haas, 2002), while other schools of thought are advocating participatory methods of teaching (Moulin, 2007). Despite these arrays of teaching methods being advocated in literature, there is no specific method that is globally acceptable. Thus, one will keep raising the question on which method is most effective, workable and acceptable to teachers and students (Moulin, 2007). The impact of these methods on the academic performance of student is at variance as they may be factorial to their success or failure (Nbina \& Obomamu, 2011). In Health Institutions where middle-health care providers are trained, their training is expected to be of optimal standard as they deal with human life. Their training should be of standard and most practical (Sajjad, 2011). Education in Nigeria has always related to evaluation process from examinations which are a result of the quality of knowledge imparted by lecturers or teachers. Some authors are of the opinion that the academic performance of students in higher institutions is grossly dependent on the method used by lecturers. Number of studies has revealed different teaching methods globally (Agboola \& Oloyede, 2007; Berry, 2008; Haas, 2002). Some of these studies focused on factors militating against effective teaching and student's individual ability as a determinant of success or failure (Senkoro, 2004; Wolfaardt, 2001). Teaching methodology can be defined in different ways depending on the philosophical situation refers to variety ways in 
which a learning task is managed to facilitate the learning process. There are two categories of teaching method, namely, teacher-centered method and learner-centered methods of teaching. Learner-centered instruction refers to the students' construct their own understanding of content; develop a personal feeling that the knowledge is their own. Therefore, student centeredness implies the heavy emphasis on enquiry and problem-based learning involves on making student as the center point of learning and group work. Each of this method is discussed in detail below:

\section{Learner (Student) Centered}

1) Question and answers (citation) method: Question and answers defined as a method both for teaching and oral testing based on the use of questions to be answered by the students.

2) Discussion method: Discussion method is an important component for any teaching or learning situation which allows students to share their ideas.

3) Brainstorming: Brainstorming is a teaching techniques in which every pupil's response that applies to a given topic is acceptable.

4) Practical Demonstration method: Demonstration is a practical display or exhibition of a process and services to show or point out clearly the fundamental principles or actions involved.

\section{Teacher-Centered}

Teacher-centered methods of teaching are the one-way communication where by the teacher delivers the material orally while the learner listens or takes down notes.

1) Lecture method: Lecture is one-way communication where teacher talks to students in an autocratic way and in its pure form, the student have no opportunity to ask questions or offer comments during the lesson.

2) Presentation method: Presentation method of teaching involves motivation listeners to accept a new idea, alter an existing opinion or act on a given premise.

3) Seminar method: Seminar method is structured group discussion that may follow after a formal lecture or some sort of experience.

\section{Factors that Influence the Choice of Teaching Method}

The choice of methods of teaching depends on different factors for example knowledge of the teacher and flexibility. In order to make an informed choice of teaching method(s) in the teaching and learning process the teacher must know; the teaching methods available, the strengths and weakness of each method, the purpose of each can save and how each method can be used in practice. Other considerations during choosing a method of teaching are number of students to be taught, age, time and prior knowledge of the learner.

\section{Objectives}

The specific objectives of this study are to:

1) Assess the effectiveness of Two-Teaching Methods (Lecture and Practical 
demonstration) in the study area.

2) Assess the Academic performance of student of the department in the study area

3) Determine the relationship between the two teaching methods and the academic performance of student in the department.

\section{Methodology}

\section{Research Design}

The authors adopted descriptive study design where in data were obtained through questionnaire. Secondary data on student academic record was obtained from the Examination and Record Unit of the Institution via the Department. The Academic Record was correlated to measure the effectiveness of the two-teaching methods in Community Health department of the Ekiti State College of Health Science and technology, Ijero. To further confirm the result of this study, lecturers from the departments were interviewed and their Reponses were discussed respectively.

\section{Study Area}

Ekiti State College of Health Sciences and Technology located in Ijero Ekiti, Nigeria. It is a state owned Health Institution that produces middle health practitioners. It is sited along Epe Road, Ijero Ekiti at Long 5.0104 and Lat. 7.7915. The department of Community Health was selected as the case study in the Institution. The department boasts of over four hundred (400) students with twenty Lecturers (Domiciled and Servicing).

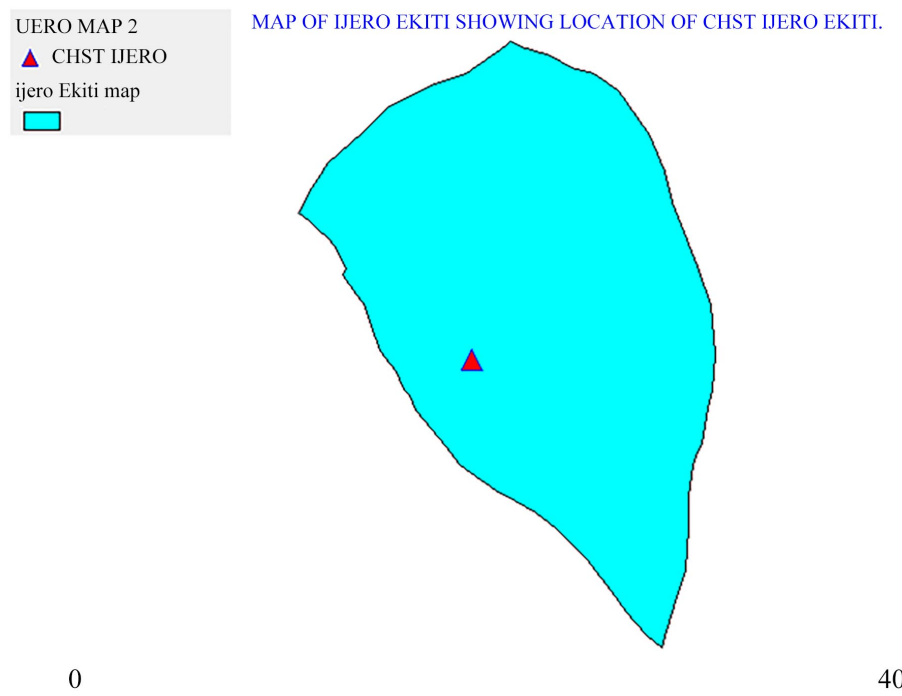

\section{Inclusion and Exclusion Criteria}

The new students of the department were excluded from the research due to unavailability of their academic record as at the time of this research work hence 200 level and 300 level were included as there are records of their academic performance. 
Sample size

$$
n=\frac{N}{N+N(e)^{2}}
$$

where

$$
\begin{aligned}
& n=\text { sample size } \\
& N=\text { total population }=400 \\
& e=\text { sampling error }=0.005
\end{aligned}
$$

$$
n=\frac{400}{1+400(0.005)^{2}}
$$

$$
\begin{aligned}
& n=400 / 1+400(0.005) 2 \\
& n=400 / 1+4.8 \\
& n=400 / 5.8 \\
& n=68.96-69 \\
& n=69
\end{aligned}
$$

Sample size $=69$

\section{Sampling Technique}

The population of the study area is Four Hundred (400) as at the time of this research work. Authors used a stratified sampling technique hence; a total of sixty-nine (69) sample was drawn from the total population of the study. Three lecturers from the department were randomly interviewed.

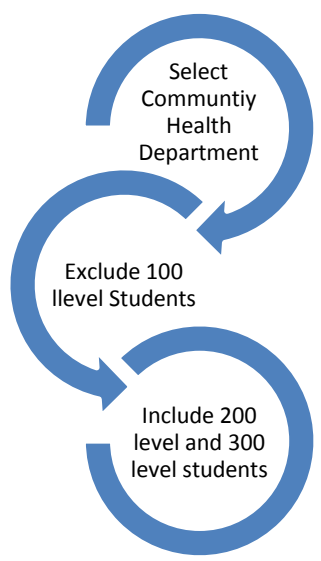

\section{Research Instrument}

The Authors used Questionnaire for data collection and also used secondary data (Academic Record) obtained from the department. Pretest of the instrument was carried out on samples different from actual sample for this study; the validity of the research instrument was carried out with result at 0.92 . The results were analyzed using SPSS and descriptive analysis of data collected.

\section{Interview}

Three lecturers from the department were randomly selected and interviewed on the teaching method utilized and its effectiveness. 


\section{Hypothesis}

Ho: There is no significant relationship between the academic performance of student and the two-teaching method in the study area.

$\mathrm{H}_{1}$ : There is significant relationship between the academic performance of student and the two-teaching method in the study area.

\section{Method of Data Analysis}

The results were analyzed using simple percentage, graphs, charts, mean, S.D, Variance, ANOVA, t-test @ 0.05 significant level using STATA MP12 and SPSS.

\section{Results}

Table 1 indicates that $63.3 \%$ of respondents (students) are female and $36.7 \%$ are male. This showed that the student's populations in the department are mostly female (Figure 1).

Table 2 shows that $37.68 \%$ of the respondents (students) chose Clinical Skills as their best course, $34.78 \%$ chose Supervised-Based Community Health Practice as their best course, $10.14 \%$ identified Health Education and Environmental Health Science as their best course respectively while 7.24\% are best in Anatomy \& Physiology. This shows that the student in the department gives much attention or priority to professional and core courses.

Table 3 shows that the students rated practical demonstration as the best and the most effective indicating $73.91 \%$ while $26.09 \%$ rated the method as effective. Lecture method was also rated to be effective at $57.97 \%$ while 42.03 rated the method as most effective. This shows that the two methods are effective as identified by the student which is the objective number one of this study (Figure 2).

Table 4 shows that most of the student performance falls under upper credit indicating $53.5 \%$ with $22.75 \%$ within the grade point lower credit. $3 \%$ of the student is on distinction which shows that $79.25 \%$ of the student in the department has good academic record. Only $5 \%$ of the entire student population in the department failed. This result achieved objective number two of this study (Figure 3).

\section{Statistical analysis using SPSS}

Ho1: There is no significant relationship between the academic performance of student and the two-teaching method in the study area.

The answer to research hypothesis one is summarized in Table 5 and Table 6.

The hypothesis (Ho): The result of the t-test in Table 5 shows that the Cal. Value is 0.662 is greater than the Tab. 0.331 hence, we reject the null hypothesis.

Table 1. Showing Sex distribution of Respondents.

\begin{tabular}{cccc}
\hline Sex & Frequency & Percent & Cumulative Percent \\
\hline Male & 25 & 36.7 & 36.7 \\
Female & 44 & 63.3 & 100.0 \\
Total & 69 & 100.0 & \\
\hline
\end{tabular}

Source Field Survey (2020). 
Table 2. Best Courses as identified by the respondents.

\begin{tabular}{cccc}
\hline Combination & Frequency & Percent & Cumulative Percent \\
\hline Anatomy \& Physiology & 5 & 7.24 & 7.24 \\
Supervised-Based CH & 24 & 34.78 & 42.02 \\
Environmental Health Sci & 7 & 10.14 & 52.16 \\
Clinical Skills & 26 & 37.68 & 89.86 \\
Health Education & 7 & 10.14 & 100.0 \\
Total & 69 & 100.0 & \\
\hline
\end{tabular}

Table 3. Rating the two-method use by lecturers in the department.

\begin{tabular}{cccc}
\hline Teaching Methods & Not Effective & Effective & Most Effective \\
\hline Practical Demonstration & Nill & $18(26.09)$ & $51(73.91)$ \\
Lecture & Nill & $40(57.97)$ & $29(42.03)$ \\
\hline
\end{tabular}

Source: Field Survey 2020.

Table 4. Academic record of student in the department.

\begin{tabular}{ccccc}
\hline Distinction & Upper Credit & Lower Credit & Pass & Fail \\
\hline $12(3 \%)$ & $214(53.5 \%)$ & $97(22.75 \%)$ & $57(14.25 \%)$ & $20(5 \%)$ \\
\hline
\end{tabular}

Table 5. t-test statistics for comparison of the post-test mean scores of the two groups.

\begin{tabular}{ccccccccc}
\hline Group & $\mathrm{N}$ & Mean & Std. Error & Std. Deviation & Df & T-value & p-value & Remark \\
\hline Experimental & 20 & 44.0 & 1.1120 & 8.2210 & 39 & 0.662 & 0.331 & Rejected \\
Control & 20 & 42.0 & 1.0624 & 7.1022 & & & & \\
\hline
\end{tabular}

Table 6. ANOVA statistic for comparison of the post-test mean scores for the two groups.

\begin{tabular}{cccccccc}
\hline Variations & $\begin{array}{c}\text { Sum of } \\
\text { squares }\end{array}$ & Df & Mean square & $\begin{array}{c}\text { Square } \\
\text { value }\end{array}$ & F-value & p-value & Remark \\
\hline Within groups & 1921.322 & 21 & 1.1120 & 82.104 & 0.664 & Rejected \\
Between groups & 1024.022 & 14 & 1.0624 & 61.241 &. & 0.610 & \\
Total & 2945.344 & 35 & & & & \\
\hline
\end{tabular}

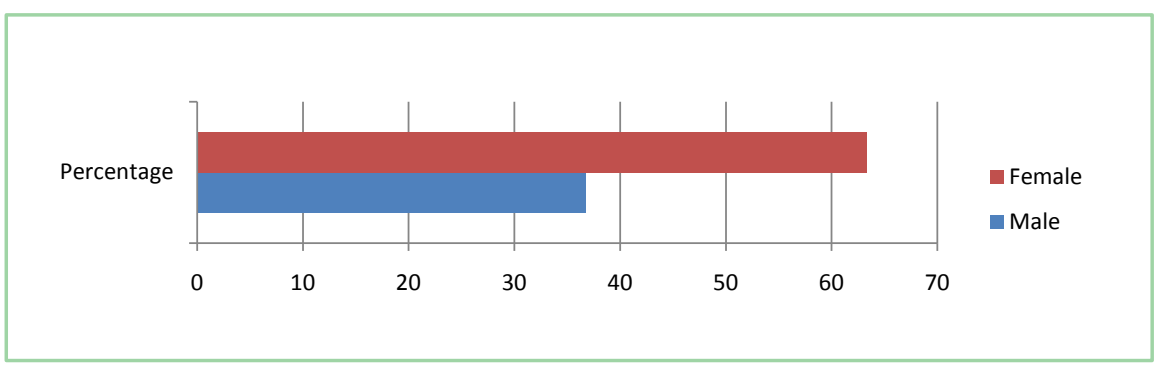

Figure 1. Sex distribution of respondents. 

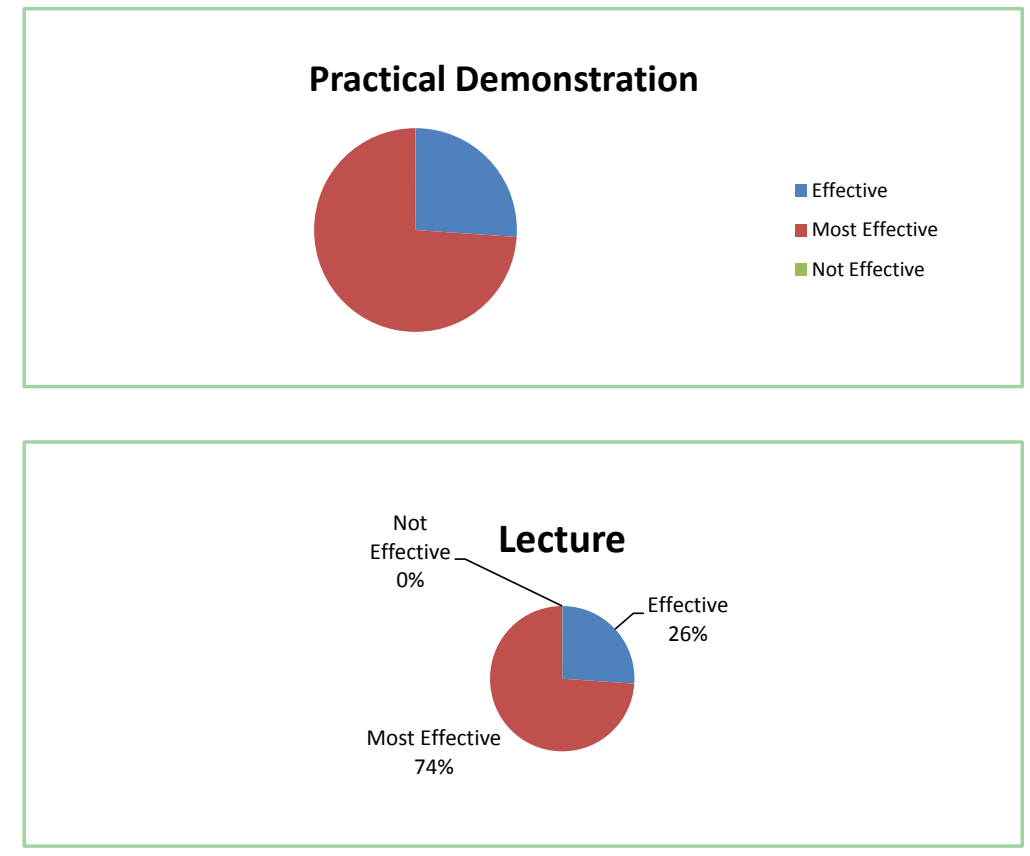

Figure 2. Chart showing rating of teaching methods used in the department.

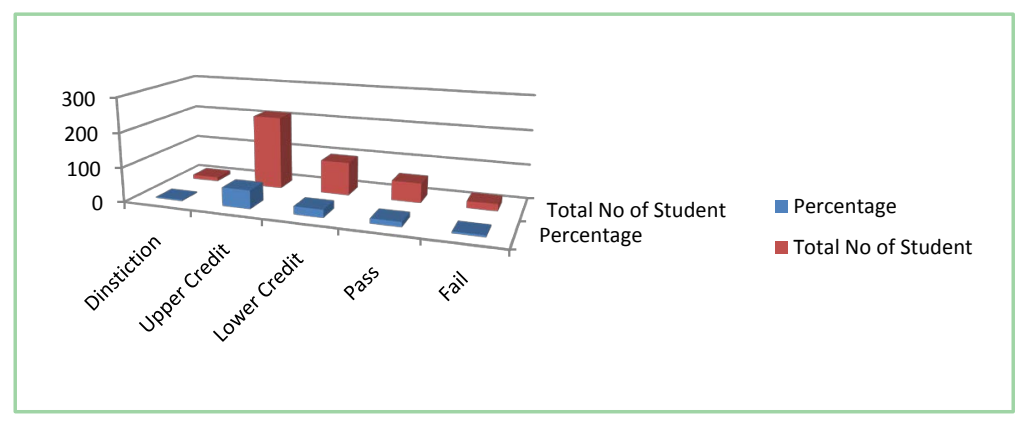

Figure 3. Showing the academic performance of student in the study area.

ANOVA was used in Table 6 and it was revealed in the statistical result that F-value 0.664 is greater than P-value 0.610 as such, we reject Ho. Therefore, the result from both tests shows that there is significant relationship between the two-teaching methods and the academic performance of students in the study area which is the objective number three of this study.

\section{Discussion}

Based on the data above, it was revealed that $63.3 \%$ of respondents (students) are female and $36.7 \%$ are male. Thirty-Seven percent (37.68\%) of the respondents (students) choose Clinical Skills as their best course, $34.78 \%$ said Supervised-Based Community Health Practice is their best course, $10.14 \%$ identified Health Education and Environmental Health Science as their best course respectively while $7.24 \%$ are best in Anatomy \& Physiology. This shows that the student in the department gives much attention or priority to professional and core courses. This study also revealed that the students rated practical demonstration 
as the best method and the most effective indicating $73.91 \%$ while $26.09 \%$ rated the method as effective. Lecture method was also rated to be effective at $57.97 \%$ while 42.03 rated the method as most effective. This shows that the two methods are effective as identified by the student which is the objective number one of this study. Most of the student performance falls under upper credit grade point indicating $53.5 \%$ with $22.75 \%$ within the grade point lower credit. $3 \%$ of the students are on distinction grade point which shows that $79.25 \%$ of the students in the department have good academic record. Only $5 \%$ of the entire student population in the department failed. This result achieved objective number two of this study. The result from both tests showed that there is significant relationship between the two-teaching methods and the academic performance of students in the study area which is the objective number three of this study.

\section{Interviews}

The authors interviewed three (3) lecturers from the department and the following are issues raised from the interviews.

The First lecturer opined that practical demonstration is the most used as method of teaching due to the fact that it is learner centered. He also stated that it influences a dynamic reaction and participation reflexes of student involved in the learning process as there are enormous room for asking of questions and discussions. He added that during evaluation, the student writes based on practical experience of what they have learned in the class and demonstration rooms.

The Second Lecturer justified the claim of the first lecturer by giving an illustration and academic record of student test after a practical demonstration which showed a high level of performance. She added that during demonstration, students are divided into groups to make it easier for her to reach out to the entire student in the most effective way.

The Third Lecturer ascertained that he utilizes Lecture-Method which is a Teacher-centered method. He said the method comes in handy when it comes to covering curriculum and syllabus, he identified its usefulness in sharing information to a large group in a short period of time as it is also useful in situations where the purpose is to provide an educational framework, theorem and ideologies which involves the use of power-point presentations and filmstrips.

Based on the above, it is further proven that there is significant relationship between the academic performance of the student and the two-teaching method in the study area.

\section{Conclusion}

Objective Number One: The Two-Teaching Methods (Practical Demonstration and Lecture) is effective in the study area.

Objective Number Two: The Academic performance of student in the study area is commendable indicating $79.25 \%$ pass rate of the student which is above average.

Objective Number Three: There is significant relationship between the Aca- 
demic performance of the Student and the Two-Teaching Method.

\section{Recommendations}

Based on the findings of this research work, it was recommended that:

1) Practical demonstration should be integrated as an effective teaching method for Health Students since it is learner centered.

2) The study can be scaled-up to cover the entire institution to further assess the effectiveness of the two methods (Lecture and Practical Demonstration).

3) Further research into other pedagogy methods and their effectiveness in health Institutions.

\section{Authors Contribution}

All authors contributed equally to this research work.

\section{Financial Support}

Authors received no financial support or grant.

\section{Conflicts of Interest}

The authors declare no conflicts of interest regarding the publication of this paper.

\section{References}

Agbele, A. T. et al. (2020). Assessment of Students' Performance in Physics Using Two Teaching Techniques. International Journal of Research and Scientific Innovation, 7, 55-59.

Agboola, O. S., \& Oloyede, E. O. (2007). Effect of Project, Inquiry and Lecture-Demonstration Teaching Methods on Senior Secondary Students' Achievement in Separation of Mixtures Practical Test. Educational Research and Review, 2, 124-126. http://www.academicjournalss.org/ERR

Asikhia, O. A. (2010). Student and Teacher Perception of the Causes of Poor Academic Performance. Journal European Social Sciences, 13, 56-63.

Berry, W. (2008). Surviving Lecture: A Pedagogical Alternative. College Teaching, 56, 149-153. https://doi.org/10.3200/CTCH.56.3.149-153

Faraday, S., Overton, C., \& Cooper, S. (2011). Effective Teaching and Learning in Vocational Education. London, UK: LSN.

Haas, M. S. (2002). The Influence of Teaching Methods on Student Achievement. Unpublished Research, Dissertation Submitted to the Faculty of the Virginia Polytechnic Institute and University.

Moulin, M. (2007). Performance Management Definition Linking Performance and Organizational Excellence. International Journal of Health Care Quality Assurance, 20, 3. https://doi.org/10.1108/09526860710743327

Nbina, J. B., \& Obomamu, B. J. (2011). Assessment of the Effects of Problem Solving Instructional Strategies on Students' Achievement and Retention in Chemistry with Respect to Location in Rivers State. World Journal of Education, 1, No. 2.

https://doi.org/10.5430/wje.v1n2p74 
Sajjad, S. (2011). Effective Teaching Methods at Higher Education Level. Unpublished Research, Submitted to the University of Karach Pakstan.

Senkoro, F. E. M K. (2004). Research and Approaches to Medium of Instruction in Tanzania Perspective Directions and Challenges. In Block Tune, Bigit. Cape Town Minds, South Africa.

Wolfaardt, D. (2001). Facilitating Learning: An Investigation of the Language Policy of Namibia Schools. University of Western Cape, South Africa. 